\title{
Analysis of Cooling Characteristics in Datacenter Using Outdoor Air Cooling
}

\author{
Yoshiyuki Inoue $^{1}$, Hirofumi Hayama ${ }^{2}$, Taro Mori ${ }^{2}$, Koki Kikuta $^{2}$ and Noriyuki Toyohara ${ }^{3}$ \\ 1. Graduate School of Engineering, Hokkaido University, Sapporo 060-8628, Japan \\ 2. Faculty of Engineering, Hokkaido University, Sapporo 060-8628, Japan \\ 3. Department of Facilities Design, Taisei Corporation, Tokyo 163-0606, Japan
}

Received: October 20, 2014 / Accepted: November 18, 2014 / Published: January 31, 2015.

\begin{abstract}
Advancement of the information society has proceeded with the development of information and communication technology, and a demand on a data center has increased. In such a situation, the number of servers is increasing in a data center. Thus, the heat density in a data center is much higher than that of usual offices. And typically, almost $40 \%$ of the total power consumption is used for cooling servers in a data center. Thus, cooling effectiveness is one of the most important factors in evaluating the value of the data center. The data center taken up in this paper is located in Ishikari, where is a cold district in Japan. Using the cool outdoor air for cooling servers helps us to cut the power consumption for cooling. This paper first assesses the efficiency of Ishikari data center measuring the temperature of seven parts in a building where the cooling air flowing. Second, this paper describes the most efficient method for the operation and estimates 1.11 of PUE (power usage effectiveness).
\end{abstract}

Key words: Data center, cooling characteristics, outdoor air cooling, PUE.

$\begin{array}{ll}\text { Nomenclature } \\ N & \text { Scale }(-) \\ \text { Subscripts } \theta & \text { Temperature }\left({ }^{\circ} \mathrm{C}\right) \\ H_{f a n} & \text { Exhaust fan load }(\mathrm{W}) \\ H_{m} & \text { Heat load }(\mathrm{W}) \\ H_{w} & \text { Heat loss on wall }(\mathrm{W}) \\ V & \text { Air conditioning supply-air volume }\left(\mathrm{m}^{3} / \mathrm{s}\right) \\ V_{f m} & \text { Effective air conditioning supply-air volume in } \\ & \text { an equipment }\left(\mathrm{m}^{3} / \mathrm{s}\right) \\ V_{f r} & \text { Effective air conditioning supply-air volume in a } \\ V_{m} & \text { room (m } / \mathrm{s}) \\ V_{O A} & \text { Equipment ventilation volume }\left(\mathrm{m}^{3} / \mathrm{s}\right) \\ V_{u m} & \text { Outdoor air introducing volume }\left(\mathrm{m}^{3} / \mathrm{s}\right) \\ V_{u r} & \text { Ineffective air conditioning supply-air volume in } \\ \Gamma & \text { an equipment }\left(\mathrm{m}^{3} / \mathrm{s}\right) \\ \theta_{0} & \text { Ineffective air conditioning supply-air volume in } \\ \theta_{0 m} & \text { a room }\left(\mathrm{m}^{3} / \mathrm{s}\right) \\ \theta_{1} & \text { Recirculation }(-) \\ \theta_{1 d} & \text { Air conditioning supply-air temperature }\left({ }^{\circ} \mathrm{C}\right) \\ \Theta_{1 m} & \text { Equipment inlet air temperature }\left({ }^{\circ} \mathrm{C}\right) \\ & \text { Air conditioning return-air temperature }\left({ }^{\circ} \mathrm{C}\right) \\ & \text { Exhausted air temperature }\left({ }^{\circ} \mathrm{C}\right) \\ \text { Equipment outlet air temperature }\left({ }^{\circ} \mathrm{C}\right)\end{array}$

Corresponding author: Yoshiyuki Inoue, graduate student, research field: engineering. E-mail: star69@ec.hokudai.ac.jp.
$\begin{array}{ll}\Theta_{\text {mix }} & \text { Mixing air temperature }\left({ }^{\circ} \mathrm{C}\right) \\ \Theta_{O A} & \text { Outdoor air temperature }\left({ }^{\circ} \mathrm{C}\right)\end{array}$

\section{Introduction}

With the rapid development in information technology in recent years, the energy consumption of datacenters follows the increasing proportion of total energy consumption in society as a whole [1-3]. In normal datacenters, air conditioning systems have to operate year round to treat a large sensible heat load. There are many efficient datacenters located in cold areas that use outdoor air cooling systems $[4,5]$. These systems play an important role in reducing the processing loads on servers. Many researchers have studied indoor air conditioning systems. Furihata et al. [6] investigated the temperature of 100 points in sever rooms and found the characteristics which show a performance of datacenters. Hayama [7] proposed a method for estimating the energy consumption of air conditioning systems using the relation between the cooling characteristics and energy consumption. 
However, there is no specific control method for saver rooms. It is important to determine the efficiency and characteristics of an outdoor air cooling system in detail. Therefore, we studied a datacenter located in Ishikari, a cold area in Hokkaido, Japan, which cools the electrical devices by outdoor air. First, we assessed the efficiency of this system by measuring the temperature of each area in the building. We then analyzed the cooling characteristics of this system by using a model for the system. Finally, we estimated the energy consumption and determined a proper management method for more efficient operation.

\section{Ishikari Datacenter}

\subsection{Summary of Facilities}

The datacenter we assessed is located in Ishikari, Hokkaido, Japan. Fig. 1 shows the building's facade, Table 1 lists the building specifications, and Fig. 2 illustrates a plan of a server room. In this datacenter, outdoor air comes into a server room from a wall. Fig. 3 shows a section of a server room. To stabilize the airflow volume, every rack has a fan on the surface of their ceiling to provide the necessary amount of cooling air.

\subsection{Actual Measurements}

We measured the temperatures at seven points around a server room from May 2012 to May 2013. Table 2 lists the details of the points and Fig. 4 illustrates where those points are located.

\subsection{Temperature Distribution}

Fig. 5 shows a boxplot of the temperature distribution obtained from the actual measurement. As a reference, there are recommended or allowable conditions in server rooms, as shown in Table 3, which were determined by ASHRAE (American Society of Heating Refrigerating and Airconditioning Engineer) (2011).

We can see that the blowout temperatures are relatively stable. They are within the limit of the ASHRAE (2011) [8] recommended temperature range

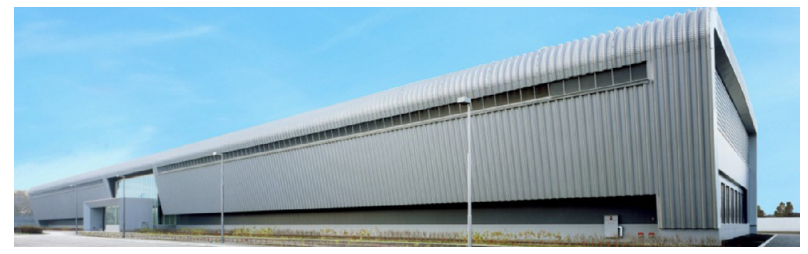

Fig. 1 The building facade.

Table 1 Specification of building.

\begin{tabular}{|c|c|c|c|}
\hline & Items & Room A & Room B \\
\hline \multirow{2}{*}{ Outline } & Floor space & \multicolumn{2}{|c|}{$302.1\left(\mathrm{~m}^{2} /\right.$ room $)$} \\
\hline & Setting condition & \multicolumn{2}{|l|}{ ASHRAE (2011) } \\
\hline \multirow{2}{*}{$\begin{array}{l}\text { Air flow } \\
\text { system }\end{array}$} & Supply air system & Wall & Ceiling \\
\hline & $\begin{array}{l}\text { Exhaust air } \\
\text { system }\end{array}$ & \multicolumn{2}{|l|}{ Exhaust tower } \\
\hline \multirow{2}{*}{$\begin{array}{l}\text { Air } \\
\text { conditioner }\end{array}$} & Fan & $\mathrm{FU} \times 4$ & $\mathrm{AHU} \times 4$ \\
\hline & Power & $12.6 \times 4(\mathrm{~kW})$ & $33.0 \times 4(\mathrm{~kW})$ \\
\hline $\begin{array}{l}\text { Exhaust } \\
\text { fan }\end{array}$ & $\begin{array}{l}\text { Power } \\
\text { consumption }\end{array}$ & \multicolumn{2}{|c|}{$1.06 \times 16(\mathrm{~kW} / \mathrm{room})$} \\
\hline \multirow{3}{*}{ Chiller } & $\begin{array}{l}\text { Number of } \\
\text { systems }\end{array}$ & \multicolumn{2}{|l|}{1} \\
\hline & Cooling capacity & \multicolumn{2}{|l|}{$1,617(\mathrm{~kW})$} \\
\hline & $\begin{array}{l}\text { Power } \\
\text { consumption }\end{array}$ & \multicolumn{2}{|c|}{$\begin{array}{l}272(\mathrm{~kW})=250(\mathrm{~kW})(\text { Chiller }) \\
+55 \times 4(\mathrm{~kW}) \\
(\text { Cooling tower })\end{array}$} \\
\hline
\end{tabular}

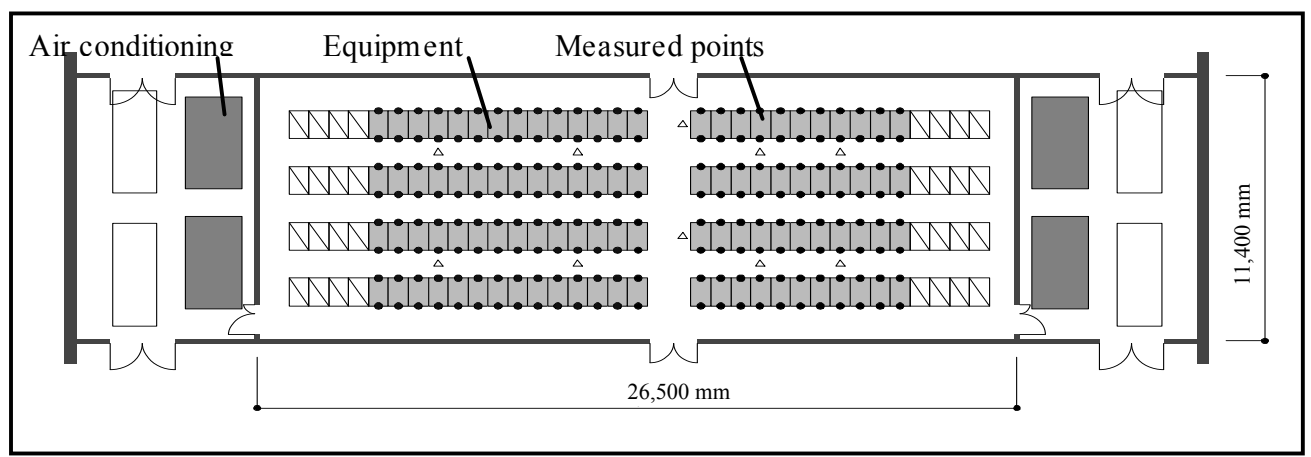

Fig. 2 The plan of the server room. 


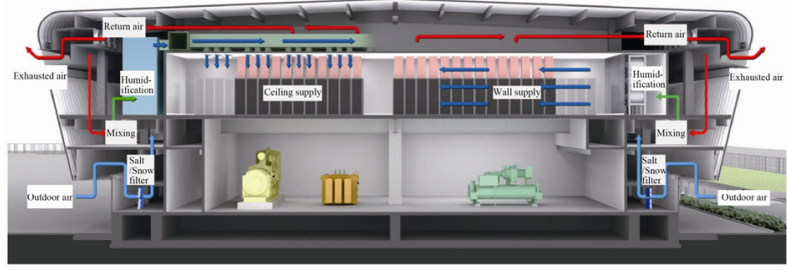

Fig. 3 The section of the server rooms.

Table 2 Measurement detail.

\begin{tabular}{llllll}
\hline Subject & Point & \multicolumn{3}{c}{ Place Number } & $\begin{array}{c}\text { Time } \\
\text { span }\end{array}$ \\
& Outdoor & T1 & 4 & & \\
& Mixing & T2 & 2 & & \\
Supply air & T3 & 3 & & \\
Temperature Inlet air & T4 & 100 & 1 day & 2012/1/1- \\
Outlet air & T5 & 100 & & \\
Exhausted air & T6 & 100 & & \\
Return sir & T7 & 4 & & \\
\hline
\end{tabular}

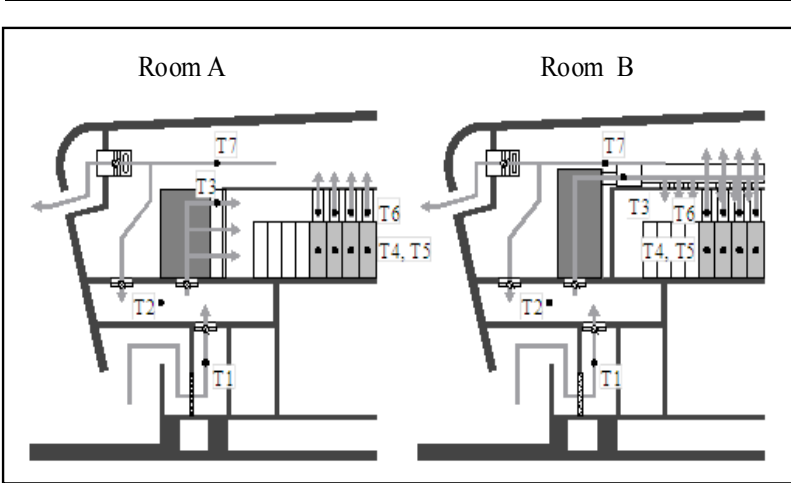

Fig. 4 The section of the datacenter.

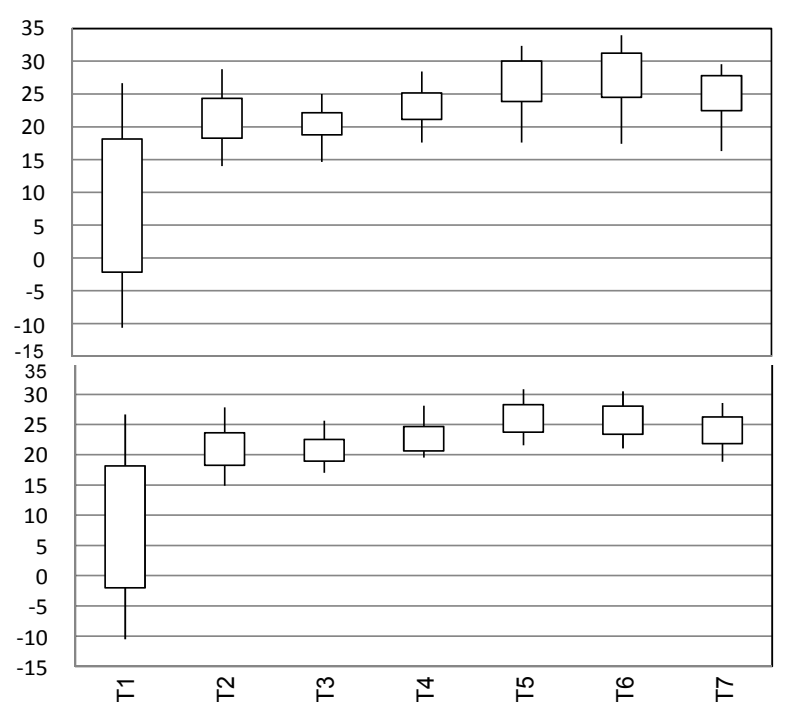

Fig. 5 Temperature distribution.
Table 3 Allowable and recommended condition (ASHRAE 2011).

\begin{tabular}{lll}
\hline & Recommended & Allowable \\
\hline Low temperature & $18{ }^{\circ} \mathrm{C}$ & $15{ }^{\circ} \mathrm{C}$ \\
High temperature & $27{ }^{\circ} \mathrm{C}$ & $32{ }^{\circ} \mathrm{C}$ \\
Low humidity & DP $5.5^{\circ} \mathrm{C}$ & RH $20 \%$ \\
High humidity & RH $60 \%$, DP $15{ }^{\circ} \mathrm{C}$ & RH $80 \%$, DP $21{ }^{\circ} \mathrm{C}$ \\
\hline
\end{tabular}

of $18-27{ }^{\circ} \mathrm{C}$ (dew point). However, there is a drop in temperature between the exhaust ports of servers (T5) and return air (T7). This means that there is a large supply of cooling air that does not pass through servers but goes directly to the spaces between the roof and ceilings. We call this phenomenon "short circuit". Because of the short circuit, there is a small gap in temperatures between supply air and return air. Moreover, there is a rise in temperature between supply air (T3) and the suction ports of servers (T4). This means that there is some cooling air passing through servers that comes back to the server room. We call this phenomenon "recirculation".

\section{Cooling Characteristics}

\subsection{Analytical Model}

To understand the cooling characteristics, we constructed the model illustrated in Fig. 5. Using this model, we can see how large the short circuit and recirculation are during operation. The meaning of signs is listed in Nomenclature. Table 4 lists the definitional equations of cooling characteristics. These equations explain how cooling air is supplied properly, irrespective of the change in outdoor temperatures.

We now discuss the air flow. First, an air conditioner supplies cooling air (temperature $=\theta_{0}\left({ }^{\circ} \mathrm{C}\right)$, volume $=V$ $\left.\left(\mathrm{m}^{3}\right)\right)$ to server rooms. Then, the supplied air $\left(V\left(\mathrm{~m}^{3}\right)\right)$ separates into effective supplied air in room $\left(V_{f r}\left(\mathrm{~m}^{3}\right)\right)$, which goes above the server racks, and ineffective supplied air $\left(V_{u r}\left(\mathrm{~m}^{3}\right)\right)$, which exhausts before reaching the server racks. The temperature of $V_{f r}\left(\mathrm{~m}^{3}\right)$ rises to $\theta_{1 d}$, called the temperature of exhausted air, while $V_{f r}$ passes through the heating servers (we define the heat load as $H_{m}\left(\mathrm{~m}^{3}\right)$ and heat loss as $\left.H_{w}\left(\mathrm{~m}^{3}\right)\right)$. After that, $V_{f r}$ 


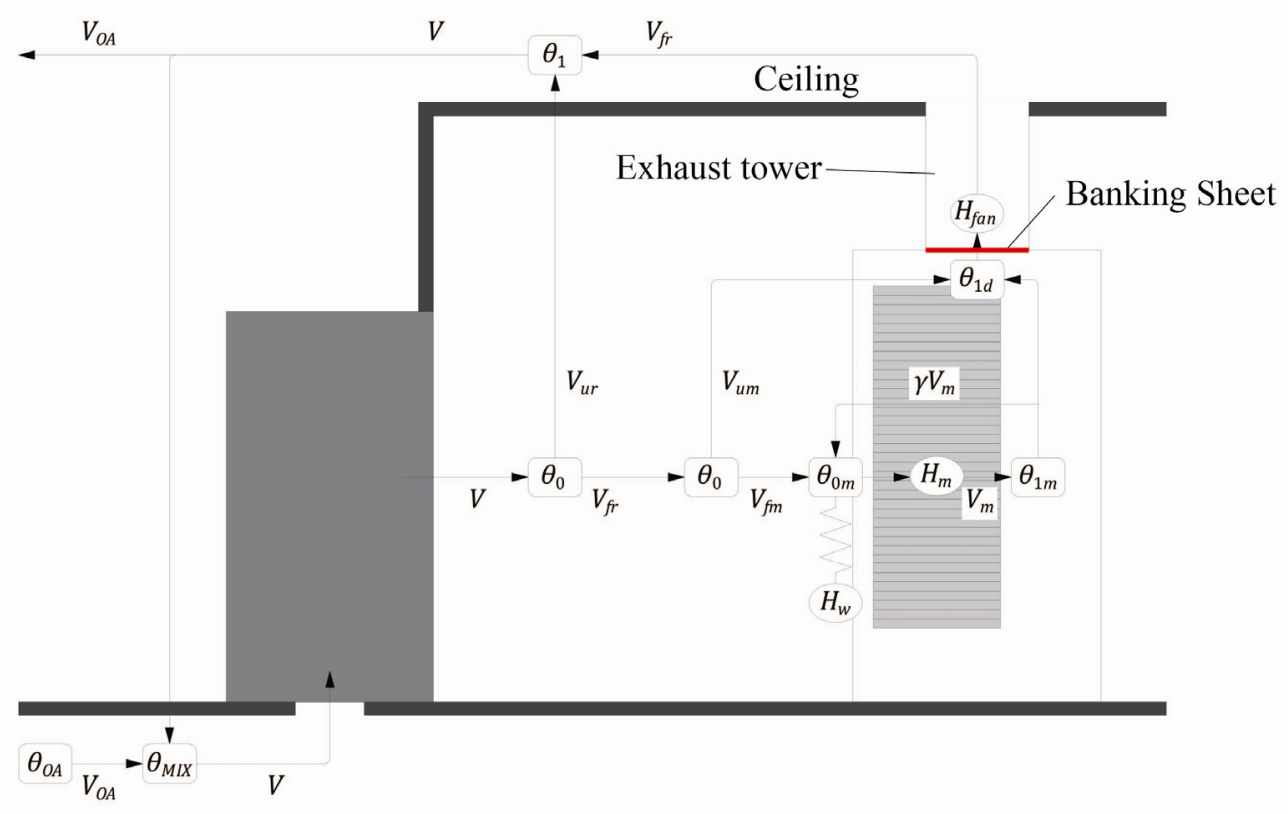

Fig. 5 Model for cooling characteristics.

Table 4 Cooling characteristics.

\begin{tabular}{ll}
\hline Ventilation flow ratio & Room exhaust efficiency \\
\hline$\kappa_{m}=\frac{V}{V_{m}}=\frac{\theta_{1 m}-\theta_{0 m}}{\theta_{1}-\theta_{0}}$ & $\eta_{V_{r}}=\frac{V_{f r}}{V}=\frac{\theta_{1}-\theta_{0}}{\theta_{1 d}-\theta_{0}}$ \\
\hline $\begin{array}{l}\text { Equipment exhaust heat } \\
\text { efficiency }\end{array}$ & Exhaust heat efficiency \\
\hline$\eta_{V m}=\frac{V_{f m}}{V_{f r}}=\frac{\theta_{1 d}-\theta_{0}}{\theta_{1 m}-\theta_{0}}$ & $\eta_{V}=\frac{V_{f m}}{V}=\eta_{V_{r}} \eta_{V_{m}}$ \\
\hline $\begin{array}{l}\text { Equipment inlet air } \\
\text { temperature ratio }\end{array}$ & $\begin{array}{l}\text { Equipment outlet air } \\
\text { temperature ratio }\end{array}$ \\
\hline$m_{0 m}=\frac{\theta_{0 m}-\theta_{0}}{\theta_{1}-\theta_{0}}=\frac{\gamma}{\eta_{V}}$ & $m_{1 m}=\frac{\theta_{1 m}-\theta_{0}}{\theta_{1}-\theta_{0}}$ \\
\hline $\begin{array}{l}\text { Exhausted air temperature } \\
\text { ratio }\end{array}$ & Recirculation ratio \\
\hline$m_{1 d}=\frac{\theta_{1 d}-\theta_{0}}{\theta_{1}-\theta_{0}}$ & $\gamma=\eta_{V} m_{0 m}$ \\
\hline$\frac{\text { Fresh air introduction ratio }}{V_{O A}}=\frac{\theta_{1}-\theta_{M I X}}{\theta_{1}-\theta_{O A}}$ & Relation equation \\
\hline \begin{tabular}{l}
$V$ \\
\hline
\end{tabular} & $\gamma=-\eta_{V} \kappa_{m}+1$ \\
\hline
\end{tabular}

is mixed with $V_{u r}$ (temperature $=\theta_{0}$ ) and the temperature of $V_{f r}$ rises to $\theta_{1}$ - the temperature of return air. Moreover, the inlet temperature of servers $\left(\theta_{0 m}\left({ }^{\circ} \mathrm{C}\right)\right)$ rises to $\theta_{1 m}\left({ }^{\circ} \mathrm{C}\right)$, while the amount of ventilation in servers $\left(V_{m}\right)$ passes through the servers; their heat load is $H_{m}\left(\mathrm{~m}^{3}\right)$. Then the air flowing through the servers is exhausted. Next, we define the recirculation ratio $(\gamma)$. This means how much air is coming back to the servers after passing through them. If the ratio is high, it is inefficient. The amount of air coming back to the servers can be expressed as $\gamma V_{m}$.

The supplied air passing through a ceiling chamber $\left(V\left(\mathrm{~m}^{3}\right)\right)$ separates into the exhausted air and return air going to the mixing chamber. The return air is mixed with fresh air (temperature $=\theta_{O A}\left({ }^{\circ} \mathrm{C}\right)$, volume $=V_{O A}$ $\left.\left(\mathrm{m}^{3}\right)\right)$, then the temperature becomes $\theta_{\text {mix }}\left({ }^{\circ} \mathrm{C}\right)$. Finally, the mixed air flows into the air conditioner.

\subsection{Cooling Characteristics}

Each characteristic calculated with the obtained temperature data is shown in Fig. 6. Basically, every temperature ratio changes in proper order. However, gaps among the temperature ratios are small, so a small amount of recirculation or short circuit may exist. Until November 2012, the exhausted air temperature ratio was lower than the equipment-exhausted air temperature ratio. 
Thus, we put a baking sheet on top of the operational server racks so as not to let the air exhaust without passing through the equipment. After we placed the sheet in November 2012, the exhausted air temperature ratio exceeded the equipment-exhausted air temperature ratio. This means the exhausted air temperature became higher than the equipment-exhausted air temperature regardless of the outside temperature.

After all, the short circuit problem in equipment - the phenomenon in which supplied air is exhausted without passing through equipment was addressed by using the baking sheet. Also, the recirculation ratio $(\gamma)$ and equipment-inlet air temperature ratio decreased after November 2012. This is because the placement rate in the server racks increased. Therefore, there is no relation between using a baking sheet and improvement in $\gamma$. Thus, we will have to consider capping the operational parts in server racks to reduce $\gamma$.

\subsection{Cooling Characteristics Evaluation}

To quantitatively verify the effect of setting a baking sheet on top of operating servers, we compared the cooling characteristics between June-July 2012 and June-July 2013, as shown in Table 5. The heat-exhaust efficiency $(\eta V)$ in 2013 (0.72), was much higher than that in 2012 (0.5). In particular, the room heat-exhaust efficiency $\left(\eta V_{r}\right)$ improved from 0.57 to 0.71 , so the

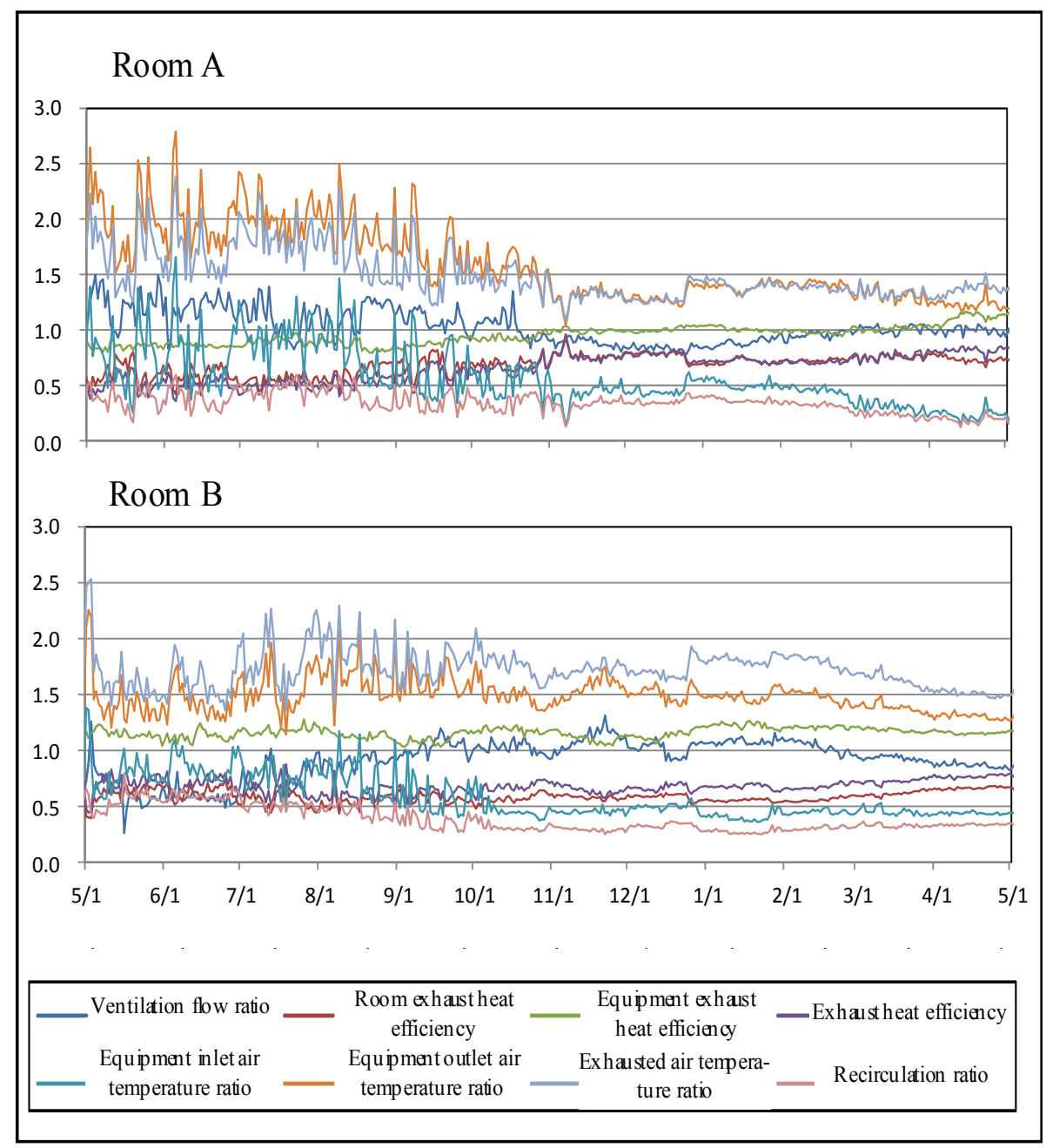

Fig. 6 Change of the cooling characteristics. 
Table 5 Results of cooling characteristics.

\begin{tabular}{|c|c|c|c|c|}
\hline & \multicolumn{2}{|c|}{ June-July 2012} & \multicolumn{2}{|c|}{ June-July 2013} \\
\hline & Room A & Room B & Room A & Room B \\
\hline Ventilation flow ratio & 1.14 & 0.68 & 0.97 & 0.88 \\
\hline $\begin{array}{l}\text { Room exhaust heat } \\
\text { efficiency }\end{array}$ & 0.57 & 0.59 & 0.71 & 0.67 \\
\hline $\begin{array}{l}\text { Equipment exhaust } \\
\text { heat efficiency }\end{array}$ & 0.88 & 1.15 & 1.00 & 1.13 \\
\hline $\begin{array}{l}\text { Exhaust heat } \\
\text { efficiency }\end{array}$ & 0.50 & 0.68 & 0.72 & 0.76 \\
\hline $\begin{array}{l}\text { Equipment inlet air } \\
\text { temperature ratio }\end{array}$ & 2.01 & 1.49 & 1.41 & 1.50 \\
\hline $\begin{array}{l}\text { Equipment outlet air } \\
\text { temperature ratio }\end{array}$ & 1.78 & 1.72 & 1.41 & 1.50 \\
\hline $\begin{array}{l}\text { Exhausted air } \\
\text { temperature ratio }\end{array}$ & 0.43 & 0.55 & 0.30 & 0.34 \\
\hline Recirculation ratio & 0.43 & 0.55 & 0.30 & 0.34 \\
\hline
\end{tabular}

baking sheet seemed to work well. We can say that there seems to be a small amount of short circuit because the equipment heat-exhaust efficiency $\left(\eta V_{m}\right)$ also improved.

The equipment inlet temperature ratio in 2013 was lower than that in 2012 by $40 \%$. This means that the gap in temperature between supply air $\left(\theta_{0}\right)$ and equipment-inlet air $\left(\theta_{0 m}\right)$ decreased and the recirculation problem was mitigated. The ventilation flow ratio $\left(\kappa_{m}\right)$ decreased from 1.14 to 0.97 . The reason of this decrease is that the number of servers decreased and the amount of supply air needed also decreased.

\section{Efficient Operation}

\subsection{Relation between Ventilation Flow Ratio and Power Consumption}

We estimated power consumption in relation to $\kappa_{m}$ with the method for estimating power consumption established by Futawatari [3]. We set parameters for the placement of a baking sheet, exhaust-air efficiency, and $\gamma$ against $\kappa_{m}$ and $\theta_{0}$ and analyzed the characteristics of power consumption.

We determined the behavior of power consumption and found the best $\kappa_{m}$. Table 6 lists the setting conditions of the analysis.

\subsection{Ideal Ventilation Flow Ratio}

Fig. 7 shows the estimation of power consumption
Table 6 Analysis condition.

\begin{tabular}{|c|c|c|c|c|}
\hline & Case A & Case B & Case C & Case D \\
\hline $\begin{array}{l}\text { Setting equipment inlet } \\
\text { temperature }\left({ }^{\circ} \mathrm{C}\right)\end{array}$ & 18.0 & 18.0 & 27.0 & 27.0 \\
\hline Banking sheet & \multicolumn{2}{|c|}{$\begin{array}{l}\text { Non-sett Setting } \\
\text { ing }\end{array}$} & \multicolumn{2}{|c|}{$\begin{array}{l}\text { Non-sett Setting } \\
\text { ing }\end{array}$} \\
\hline Analysis time (h) & \multicolumn{4}{|c|}{$24(\mathrm{~h}) \times 365($ day $)=8,760(\mathrm{~h})$} \\
\hline Heat load (kWh/h) & \multicolumn{4}{|c|}{188} \\
\hline $\begin{array}{l}\text { Equipment quantity of } \\
\text { ventilation }\left(\mathrm{m}^{3} / \mathrm{s}\right)\end{array}$ & 48.2 & & & \\
\hline
\end{tabular}

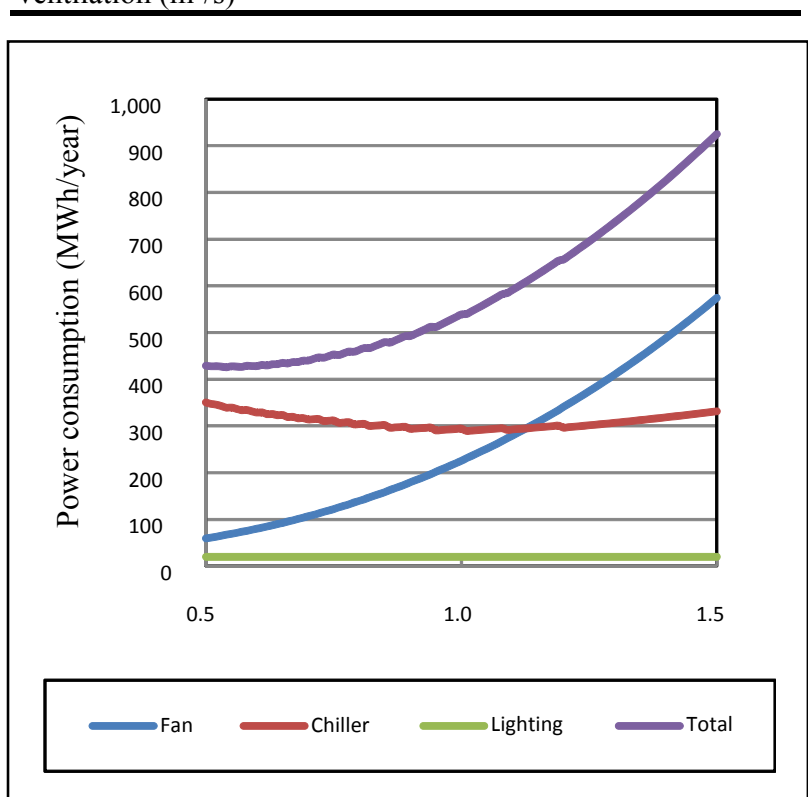

Fig. 7 Estimation of power consumption against ventilation flow ratio in a year.

against $\kappa_{m}$ in one year for each condition in Table 6 .

This graph illustrates that there is an exponential relation between power consumption and $\kappa_{m}$.

Thus, to maximize efficiency, it seems best to reduce $\kappa_{m}$. However, a low $\kappa_{m}$ is detrimental for proper operation. If $\kappa_{m}$ is too low, the circulation ratio increases. A high circulation ratio causes rapid rise in $\theta_{0 m}$, which leads to server breakdown. Moreover, when $\kappa_{m}$ is too low, $\theta_{0}$ decreases, which is also detrimental for servers. In this section, we discuss the most efficient $\kappa_{m}$. To do this, we have to consider two factors: $\theta_{0}$ and $\gamma$.

\subsubsection{Supply Air Temperature}

Fig. 8 illustrates the relation between estimated power consumption and $\theta_{0}$ against $\kappa_{m}$. According to ASHRAE, the lowest $\theta_{0}$ within the allowable range is $15^{\circ} \mathrm{C}$ [1]. Thus, $\theta_{0}$ should be higher than $15^{\circ} \mathrm{C}$. Then 


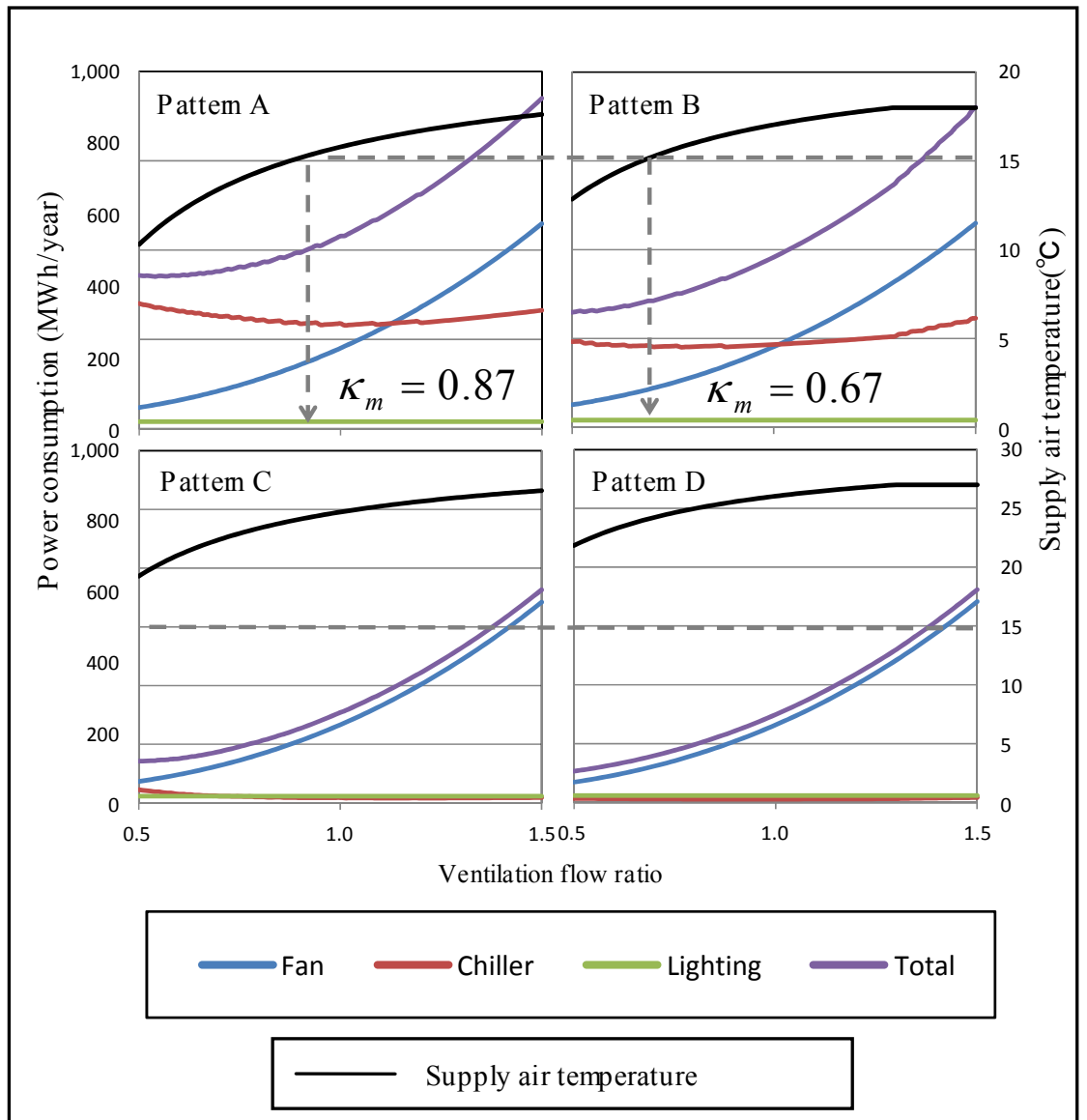

Fig. 8 Power consumption and supply air temperature against ventilation flow ratio in a year.

the best $\kappa_{m}$ is when $\theta_{0}$ is $15{ }^{\circ} \mathrm{C}$, which is 0.87 in pattern $\mathrm{A}$ and 0.67 in pattern B. However, we could not determine the best value, especially in patterns $\mathrm{C}$ and $\mathrm{D}$, because even the lowest $\kappa_{m}$ does not result in a $\theta_{0}$ below $15{ }^{\circ} \mathrm{C}$. The reason is that $\theta_{0 m}$ is so high that $\theta_{0}$ would not be outside the allowable range.

As a whole, we can say that it is better for efficient operation to set a high $\theta_{0 m}$. When $\kappa_{m}$ is 1.0 , the power consumption is $483 \mathrm{MWh} /$ year in pattern $\mathrm{A}, 479$ $\mathrm{MWh} /$ year in pattern B, $261 \mathrm{MWh} /$ year in pattern $\mathrm{C}$, and $249 \mathrm{MWh} /$ year in pattern $\mathrm{D}$. To maximize efficiency and determine the most appropriate $\kappa_{m}$ in patterns $\mathrm{C}$ and $\mathrm{D}$, we considered the allowable range of $\gamma$.

\subsubsection{Consideration of Recirculation Ratio}

We calculated and led the allowable range of $\gamma$ by considering the defined equation for cooling characteristics and the allowable range of supply air defined by ASHRAE [1]:

$$
18 \leq \frac{\theta_{0 m}-\theta_{1 m} \cdot \gamma}{1-\gamma} \leq 27
$$

The yearly average difference between equipment-exhaust air temperature and $\theta_{0 m}$ is $4.8^{\circ} \mathrm{C}$. With this value, we computed the allowable range of $\gamma$.

(1) $\theta_{0 m}$ was set to $18^{\circ} \mathrm{C}$ (for patterns $\mathrm{A}$ and $\mathrm{B}$ ):

$$
0 \leq \gamma \leq 2.2
$$

(2) $\theta_{0 m}$ was set to $27^{\circ} \mathrm{C}$ (for patterns $\mathrm{A}$ and $\mathrm{B}$ ):

$$
0 \leq \gamma \leq 0.6
$$

Considering these allowable ranges, we show the relation between power consumption and $\gamma$ with $\kappa_{m}$ in Fig. 9.

In patterns $\mathrm{A}$ and $\mathrm{B}$, we already obtained the proper values of 0.87 and 0.67 . We can confirm that these values are safe by the graph shown as Fig. 8 . 


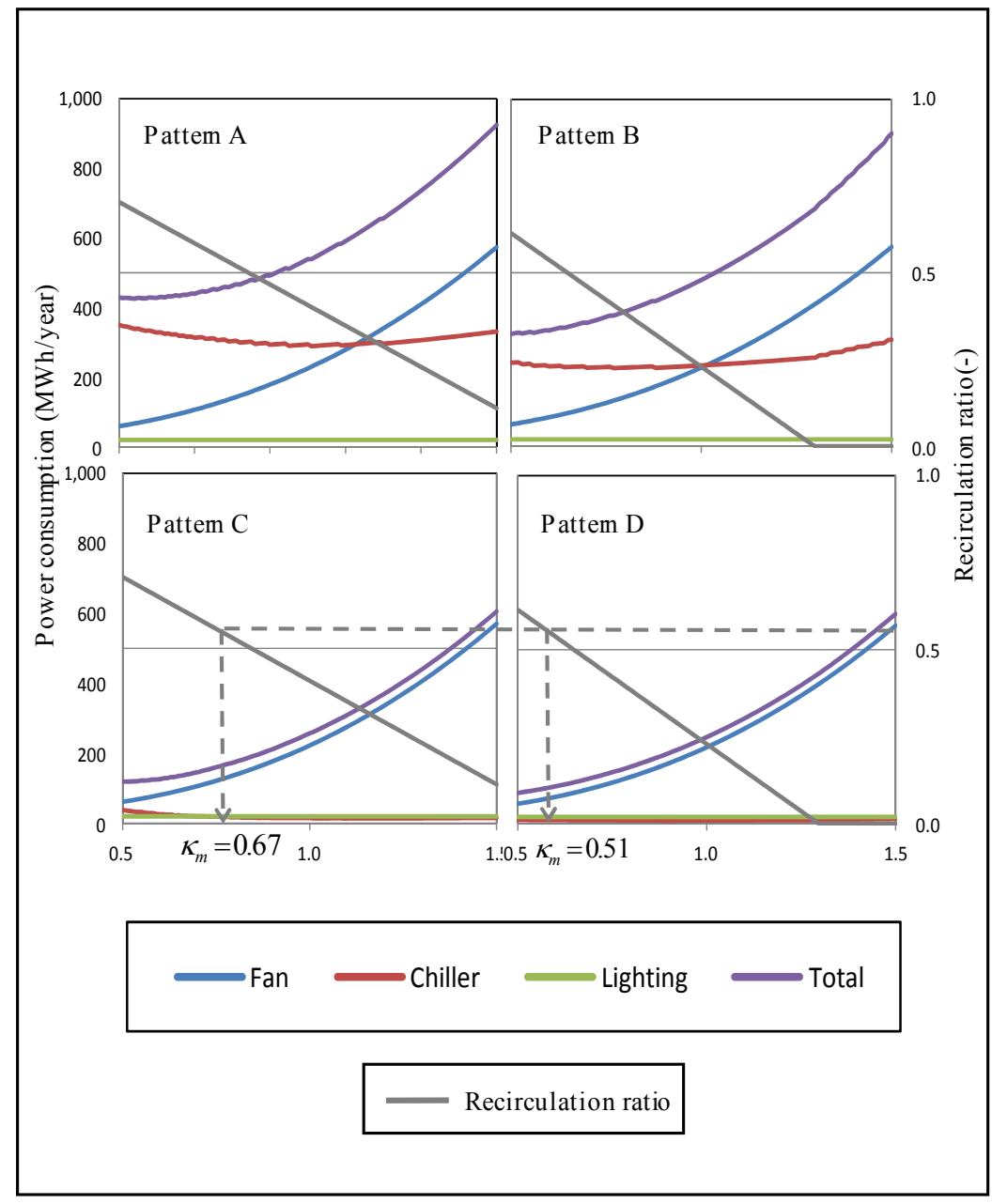

Fig. 9 Power consumption and recirculation ratio against ventilation flow ratio in a year.

\section{Table 7 Results of Analysis}

\begin{tabular}{lllll}
\hline Pattern & $\kappa_{m}$ & $\begin{array}{l}\text { Power } \\
\text { consumption PUE } \\
\text { (MWh/year) }\end{array}$ & $\begin{array}{l}\text { ICT power consumption } \\
\text { (MWh/year) }\end{array}$ \\
\hline $\mathrm{A}$ & 0.87 & 483 & 1.29 & $188(\mathrm{kWh} / \mathrm{h}) \times 8,760$ \\
$\mathrm{~B}$ & 0.67 & 349 & 1.25 & $\mathrm{~h}) \times 10^{-3}=1,646$ \\
$\mathrm{C}$ & 0.67 & 184 & 1.12 & $(\mathrm{MWh} /$ year $)$ \\
$\mathrm{D}$ & 0.51 & 175 & 1.11 & \\
\hline
\end{tabular}

We determined the best $\kappa_{m}$ in patterns $\mathrm{C}$ and $\mathrm{D}$, which is 0.67 in pattern $C$, and 0.51 in pattern $\mathrm{D}$. The results of the analysis are listed in Table 7 . We obtained the most effective operation in pattern $\mathrm{D}$. The $\theta_{0 m}$ was set to $27^{\circ} \mathrm{C}$, after placing a baking sheet, $\kappa_{m}$ was 0.51 , and the annual power consumption was 175 $\mathrm{MWh} /$ year.

Therefore, PUE (power usage effectiveness) can be estimated as 1.11 , which is better than the measured
PUE of 1.20. The PUE is equal to the entire power consumption in the datacenter divided by the power consumption for cooling heated servers. Thus, the PUE 1.11 means that only $11 \%$ of all the power is used for cooling equipment.

\section{Conclusions}

We presented the cooling characteristics of a datacenter located in Ishikari, Hokkaido, Japan. This datacenter, which uses an outdoor air cooling system, can take in fresh air to cool servers. We assessed the cooling characteristics based on temperature measurements in the building and server rooms and determined a more effective operation method for cooling servers.

We first measured the temperature of seven points in 
a building through which the cooling air from outside passes. We then found two problems in the server rooms: short circuit and recirculation. To solve these problems, we placed baking sheets on top of server racks that were not in operation. The baking sheets worked well to slow down the supplied air from leaking out into the ceiling chamber. We also constructed a model to determine the cooling characteristics in detail regardless of outdoor temperature. We defined the cooling characteristics as equations. From those equations, we found that there were still short circuit and recirculation.

We determined the most efficient operation method. We first set four patterns that differed in the temperature of equipment-inlet air and whether banking sheets were used. We estimated the power consumption in a year against the ventilation flow ratio. From that graph, we found there is an exponential relation between power consumption and ventilation flow ratio. It seemed to be the most appropriate to reduce the ventilation flow ratio to maximize efficiency.

However, too low a ventilation flow ratio causes equipment breakdown because the supply-air temperature decreased to below $15{ }^{\circ} \mathrm{C}$, the lowest temperature of supply air in the allowable range. Also, low ventilation flow ratio increases the recirculation ratio. Under a high recirculation ratio, servers cannot be cooled enough to be safe.

Thus, we considered these two factors to determine the most effective operation method. In pattern D and with a ventilation flow of 0.51 , we showed that this datacenter can be under control with an annual power consumption of $175 \mathrm{MWh} /$ year for cooling servers and PUE 1.11. However, further efforts are still required to consider the relation between the failure rate of servers and supply-air temperature. As the effective way of operation is presented in this paper, further efforts are still required to consider the relation between the failure rate of servers and the temperature of supply air.

\section{Acknowledgement}

We would like to thank to the members in Sakura Internet Corporation for letting us measure the temperature of server rooms in Ishikari Datacenter. Last but not least, this paper was supported by JSPS KAKENHI Grant Number 26289199.

\section{References}

[1] ASHRAE. 2011. Thermal Guidelines for Data Processing Environments. Atlanta: American Society of Heating, Refrigerating and Air-Conditioning Engineers, Inc..

[2] Belady, C. L. 2007. "In the Data Center, Power and Cooling Costs More than the IT Equipment It Supports." Accessed June 20, 2013. www.electronics-cooling. coml2007/021.

[3] Hamilton, J. 2008. "Cost of Power in Large-Scale Data Centers." Accessed May 14, 2013. http://perspectives.mvdirona.com/2008/11/28/CostOfPow erInLargeScaleDataCenters.aspx.

[4] Open Compute Project. 2011. "The Open Compute Server Architecture Specifications.” Accessed July 5, 2013. http://www.opencompute.org.

[5] Datacenter. 2011. "Quarterly PUE Benchmark Data." Accessed June 25, 2013. http://www.google. com/corporate/datacenter/efficiency-measurements.html.

[6] Furihata, Y., Hayama, H., Enai, M., and Mori, T. 2003. "Efficient Cooling System for IT Equipment in a Datacenter." In Proceedings of INTELEC'03 the 25th International Telecommunications Energy Conference, 152-9.

[7] Hayama, H. 1997. "Cooling Characteristics of Computer and Consideration of Energy Consumption Measures." Journal of Architecture, Planning 494: 29-36.

[8] ASHRAE. 2011. Thermal Guidelines for Data Processing Environments-Expanded Data Center Classes and Usage Guidance. Whitepaper prepared by ASHRAE Technical Committee (TC) 9.9 Mission Critical Facilities, Technology Spaces, and Electronic Equipment. 